\section{INCREASE PRODUCTIVITY AND IMPROVE TREATMENT OUTCOMES}

ConnectDental is the new specialist division of Henry Schein Dental and its launch at this year's BDTA Dental Showcase received a very positive response from dentists.

From consultancy and expertise, to technology and materials, ConnectDental helps dentists and dental technicians increase productivity and improve treatment outcomes. ConnectDental is responsible for all elements of the digital workflow, from digital impressions to final restoration, including hardware, materi- als and the unique DDX (Digital Dental Exchange). DDX is an encrypted online case management and communication platform that allows practices to securely communicate with any DDX-enabled laboratory, providing a traceable system that links every aspect of the restorative process.

Achieving smooth and efficient communication between dentist and technician is the key to producing optimum results for patients.

For a limited period, a free trial of DDX is available to enable you to appreciate how seamless and highly effective communication can improve your treatment workflow.

To find out more call 0800102041 or visit www. henryschein.co.uk

\section{INDEPENDENT IMAGING ADVICE}

Planning, delivery, installation and training are all part of the service when you order a new imaging system from The Dental Directory. The new equipment can be up and running with minimum disruption to your practice.

While some suppliers are tied to a particular imaging system, The Dental Directory carefully guards its independence so that you can be confident of getting the very best impartial advice.

You can choose from leading global manufacturers such as Dexis, Gendex, Acteon, Soredex, Vatech and Durr without being encouraged to take the product most suitable to your supplier. The Dental Directory strives to find the right product for you.

Attractive finance packages are available to fit in with your business objectives, allowing flexibility in the way you invest in your practice.

Call The Dental Directory today on 0800585585 for your copy of the equipment and digital imaging catalogue or to find out more.

\title{
THOUSANDS OF CHAIRS ALREADY INSTALLED
}

If you're looking for a new dental chair and are interested in the A-dec 500.three then you're in great company. A-dec has been chosen as the sole supplier of 129 dental chairs at the new $£ 50$ million Birming-

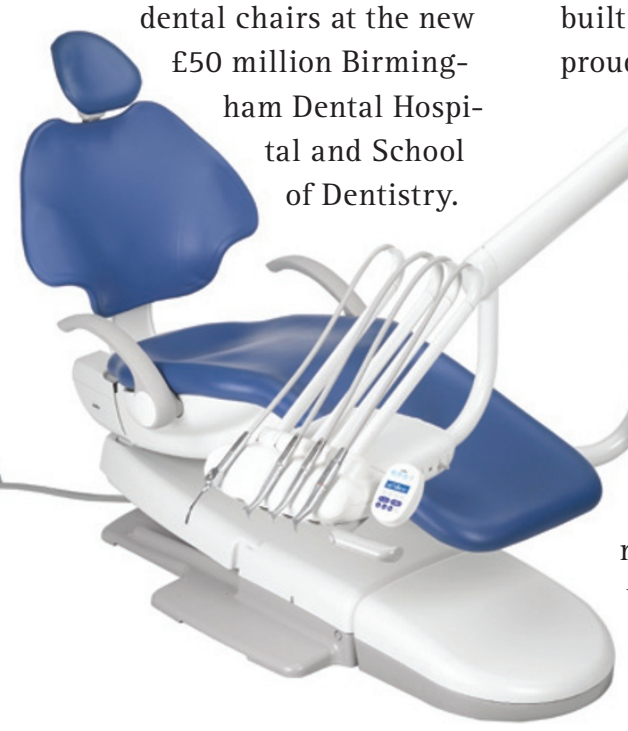

This exciting development, to be built on the former home of BBC Pebble Mill Studios, will be opening its state of the art facilities in spring 2015.

Work has already begun on the first integrated, stand-alone dental hospital and dental school to be built in the UK for almost 40 years and A-dec are proud to be supplying all of the dental equipment. After careful consideration, the project team chose the A-dec 500.three chair with seamless Sky Blue upholstery combined with the award winning A-dec LED light for each package.

This new project, coupled with the 111 A-dec 500 chairs installed at Barts and the London in 2013, plus over 2,000 dental units installed across UK and Irish schools over the last 15 years, means you can be sure you're in great company with A-dec.

For more information call 0800233285 or visit www.a-dec.co.uk.

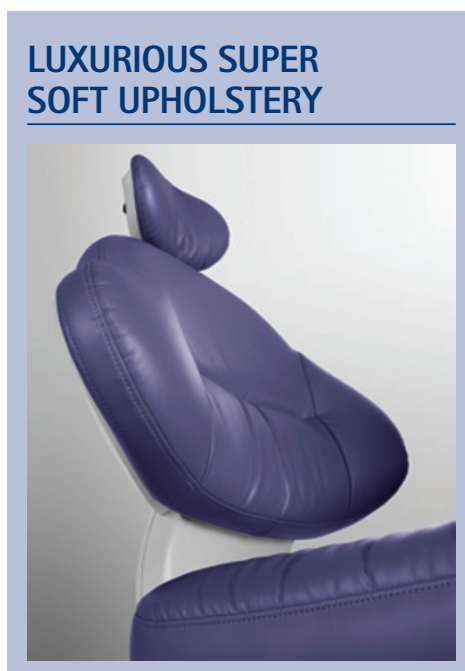

When purchasing a chair for your home you would rightly consider comfort to be as important a factor (if not more so) than aesthetics. The same should also be the case when considering a new chair for the surgery. Good looks can sometimes belie the comfort of a dental chair, which is why Takara Belmont now offer their luxurious super soft upholstery on a wider range of treatment centres, ensuring patients are as relaxed and comfortable as possible. Not only is this new range of upholstery ultra-soft, by virtue of its additional padding and quilted stitching, it's also available in a large range of colours.

A comfortable and reliable operating chair is a prerequisite for a relaxed working environment. If your patients are not positioned properly they may experience discomfort especially when undergoing lengthy treatments. Many patients are also unaware of the investment and functionality of a Treatment Centre, so the new Ultrasoft range is a tangible benefit for them. Therefore, if you want to do as much as you can to make a rarely enjoyable experience a relaxing one, contact Takara Belmont on 02075150333 or emaildental@takara.co.uk. 